\title{
Paraganglioma of the Carotid Glomus
}

\author{
Soumia Berrad*, Hayat Erraichi, Karima oualla, Lamiae Nouiakh, lamiae amaadour, Zineb \\ Benbrahim, Samia Arifi and Naoufal Mellas
}

Department of oncology, Hassan II university hospital center, Morocco

*Corresponding author: Soumia Berrad, Department of oncology, Hassan II university hospital center, Fez Morocco.

To Cite This Article: Soumia B, Hayat Erraichi, Karima o, Lamiae N, lamiae a, et al. Paraganglioma of the Carotid Glomus. Am J Biomed Sci \& Res. 2021 - 12(4). AJBSR.MS.ID.001771. DOI: 10.34297/AJBSR.2021.12.001771.

Received: 泚 March 08, 2021; Published: 觜 April 19, 2021

\begin{abstract}
Paragangliomas are very rare tumors. Carotid paragangliomas are the dominant localization. Diagnosis is relatively simple both clinically and paraclinically. The main problem is to systematically diagnose an isolated cervical tumefaction in a middle-aged subject.

Anatomo-pathology is the only test of certainty, without being able to affirm the malignant character of the primary lesions. Various medical imaging techniques are used to diagnose and pre-treat paragangliomas. This assessment aims to propose an adapted and standardized management of the patient, as well as to the members of his family in the hereditary forms.

The treatment of carotid paragangliomas is above all surgical. The removal of these tumors presents a variable difficulty, in some cases the alternative may be radiotherapy, as well as systemic therapy. The objective of the subject is to highlight this rare malignant pathology, by describing the different clinical, radiological and anatomopathological aspects of the paraganglioma as well as the modalities of therapeutic management.

In this article, we report the case of a 71-year-old patient with carotid paraganglioma who benefited from an embolization in 2011, intraoperatively because of the very important fibrous reaction and the invasion of the vascular and nervous elements and because of the high risk of vascular and neurological complications, Surgery was refused and external radiotherapy is currently indicated. The patient presents with a locoregional and distant relapse at bone and lung level, histologically confirmed, and is being treated in the medical oncology department of the Hassan II University Hospital in Fez.
\end{abstract}

\section{Introduction}

Paragangliomas are rare tumors that represent $0.03 \%$ of all neoplasias of the human body, generally benign.

These tumors derive from paraganglions, clusters of neuroendocrine cells scattered throughout the body [1-3].

Carotid paragangliomas account for 60 to $70 \%$ of paragangliomas in the cervico-encephalic region [4-6]. Diagnosis is relatively easy both clinically and paraclinically. The whole problem is to systematically evoke it when faced with an isolated cervical swelling in a middle-aged subject.

Anatomo-pathology is the only test of certainty, without being able to affirm the malignant character of the primary lesions. Various medical imaging techniques are used to diagnose and pretreat paragangliomas. This assessment aims to propose an adapted and standardized management of the patient, as well as to the members of his family in the hereditary forms.
The treatment of carotid paragangliomas is primarily surgical $[5,7]$. Removal of these tumors presents varying degrees of difficulty, in some cases by radiotherapy, and in others by systemic therapy.

\section{Case Report}

71 year old patient admitted in July 2020 for a right laterocervical mass, followed by arterial hypertension, there was no similar case in the family before. The onset of symptomatology goes back to 9 years before her admission, by the installation of an isolated right laterocervical swelling; gradually increasing in volume without other associated signs. The patient initially consulted a general practitioner where an ultrasound scan of the cervical region was requested, which objectified a right, echogenic, well-limited, relatively homogenous, well-vascularized tissue mass located at the carotid bifurcation.It benefited from an embolization in 2011, intraoperatively, given the very important fibrous reaction and the invasion of the vascular and nervous elements and given the high 
risk of vascular and neurological complications, the surgery was recused and an external radiotherapy was indicated.

In 2012, she benefited from 24 sessions of external radiotherapy. Since 2019, the patient presented pain in the sterno-clavicular joint, having benefited from a biopsy of the right clavicular mass which came back in favor of a paraganglioma. Cervico-thoracic CT scan objectivizing a cervical carotid tumor process, presence of micronodules and solid nodules of the left $8 \mathrm{~mm}$ Fowler and of the postero-basal segment of the Left Inner Lobe of 3mm, Osteolytic lesion in the medial clavicle, sternal manubrium, anterior arch of L4 and body L3.

TAP CT scan showing the cervical stage Presence of osteolytic lesions of the arch of the skull. Presence of a tissue mass centered on the IFA in its cervical path, measuring $45 * 32 * 40 \mathrm{~mm}$, this process includes the IFA, which remains permeable downstream and pushes the JIA out - Bilateral cervical lymph node formations in the carotid jugulo and spinal small infracameral axis - Thoracic stage: - Subpleural LIG nodule measuring $7 \mathrm{~mm}$ of suspicious large diameter - Voluminous tissue mass centered on the sterno-clav joint measuring $10 * 5 \mathrm{~cm}$ of large diameter - Voluminous tissue mass centered on the sternal manubrium with extension to the neighboring PM and towards the anterior mediastinum measuring $6.5 * 7.5 \mathrm{~cm}$ of grd diameter - Voluminous osteolytic mass centered on the $3^{\text {rd }}$ rib, measuring $8.5^{*} 4.5 \mathrm{~cm}$ of large diameter.

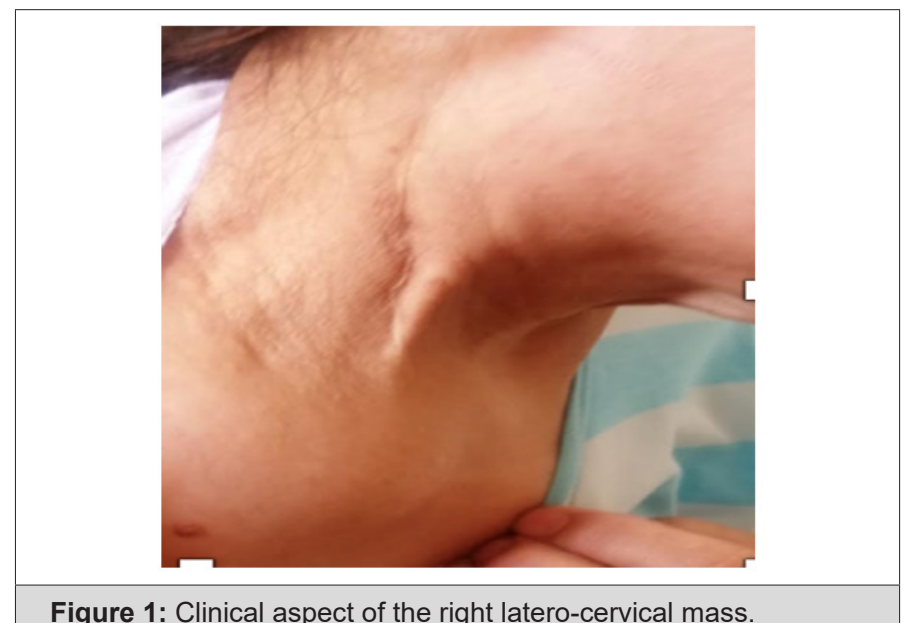

Figure 1: Clinical aspect of the right latero-cervical mass.

Abdomino-pelvic staging: - Voluminous tissue mass centered on the CVs of L4-L5 with crossing of the post wall and endocanal extension measuring $5^{*} 4.5 \mathrm{~cm}$ of the large diameters with $\mathrm{CM}$ at this level - Poorly limited osteolytic lesions involving the 2 iliac bones. The biological assessment objectified methoxyl derivatives of catecholamines Adrenaline standard at $95 \mathrm{nmol} / 24 \mathrm{~h}$ or 17 micrograms/24h and Met adrenaline: $76 \mathrm{nmol} / 24 \mathrm{~h}$ or 15 micrograms/24h 3 and ortho methyldopamine $239 \mathrm{nmol} / 24 \mathrm{~h}$ or 40 micrograms $/ 24 \mathrm{~h}$. Patient benefited from a single session of 8 gy RTH decompression therapy followed by $50 \mathrm{mg}$ daily for 4 consecutive weeks, followed by a 2 -week treatment window. patient is under good control under treatment since July 2020 (Figure $1 \& 2$ ).

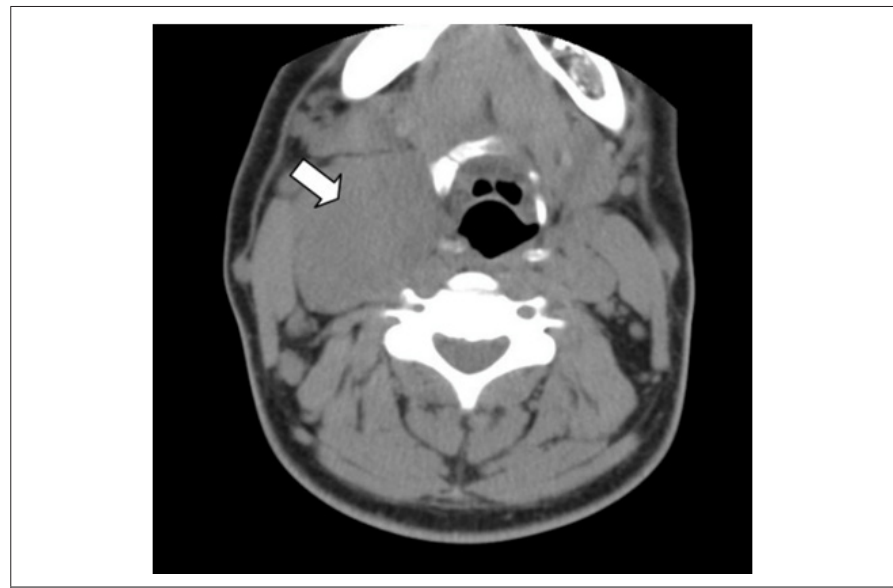

Figure 2: Cervical CT scan in axial section, without contrast agent, objective a homogeneous mass of the region right carotid (arrow).

\section{Discussion}

Paragongiomas are rare neuroendocrine tumors that develop from paragangliomas. They are usually benign and slow growing. Diagnosis is relatively easy both clinically and paraclinically, the problem is to systematically evoke it in front of a laterocervical swelling. Paragangliomas are rare tumors; they represent $0.03 \%$ of all neoplasias and $0.6 \%$ of head and neck tumors [3,8]. Carotid paragangliomas represent (60-70\%) of paragangliomas of the head and neck $[5,9,10]$. Familial forms account for $10 \%$ of cases $[11,12]$. Lesions are bilateral in $40 \%$ of cases [11]. Multiple localizations of paragangliomas are found in about $4 \%$ of sporadic forms and $30 \%$ of hereditary forms, i.e. about $20 \%$ for all forms combined [13].

There is a predominance of females in most of the series, the sex ratio Female to Male is very variable from one series to another $[14,15]$. Clinical latency is the rule and no clinical signs are specific $[7,13]$. The highly vascular and locally invasive nature of carotid paragangliomas is at the origin of the clinical symptomatology that insidiously sets in and is dependent on the volume of the tumor.

The purpose of the work-up performed for a paraganglioma is to confirm the diagnosis, to specify its size, local invasion, to evaluate the possibility of performing a total tumor resection, to search for secondary localizations and to perform a possible preoperative embolization [6].

The ultrasonographic aspect of carotid paragangliomas is that of a heterogeneous, hypoechoic mass located in the carotid bifurcation [7,16,17]. Differential ultrasound diagnosis with other cervical tumors, particularly certain highly vascularized adenopathies, may be difficult. It is therefore an examination that allows a certain degree of orientation. Any cervical tumor that is vascularized on ultrasound must be evaluated by other imaging tests [7]. The CT scan provides information on the vascular nature 
of the tumor, its location, as well as any intracranial infiltration and the presence of contralateral paraganglioma [16]. It ensures a precise analysis of the tumor by defining morphological and topographical characteristics [2,9]. The paraganglioma appears as a homogeneous, sharply contoured tissue mass of average tissue density. During iodine injection, the contrast is rapid, intense and fleeting due to vascular lavage phenomena. Distinguishing carotid vessels can be difficult when they are enclosed by a corpuscular tumor $[7,9]$.

Magnetic Resonance Imaging This is the exam of choice. It gives a precise evaluation of the locoregional extension by performing slices in the three planes of space $[9,18]$ and shows the hypervascularization of tumors thanks to angiography sequences in multiplanar slices [7]. Selective angiography is no longer essential to confirm the diagnosis of paraganglioma [7,9]. It is used less and less. It is used for therapeutic purposes, particularly when an indication for embolization has been selected, especially in large tumors and in multifocal forms, i.e. jugulo-tympanic localization [7].

The ability of paragangliomas to synthesize neuropeptides is not always clinically translated. Indeed, although all paragangliomas have neurosecretory granules, only 1 to $3 \%$ are functional or secretory [19].

To be symptomatic, the level of noradrenaline must be 4 to 5 times normal. This level can be measured in the blood (serum catecholamine) and also in the urine (urinary catecholamines) so the CATECHOLAMINE DETERMINATION It is performed in front of the presence of clinical signs suggesting a secretory paraganglioma in order to prevent the effects of catecholamine discharges during anesthetic induction or surgical manipulations. In two reviews of the literature, out of 600 carotid paragangliomas published in 1998, only 13 were functional (2\%), among them, even rarer, secreting dopamine. These old figures seem to overestimate the incidence of functional paragangliomas, which is however less than 3\% [7]. This assessment includes a 24-hour urine test for catecholamine derivatives $[11,20]$. Anatomically The carotid region and located on the anterolateral part of the neck; behind and outside the parotid, supra-hyoid and sub-hyoid regions, and in front of the supraclavicular region. It is called the carotid region because it is crossed by the carotid arteries from bottom to top. It responds to the sternocleido-mastoid muscle, its superficial limits are represented by the edges and extremities of this muscle.

Embryologically, paraganglia are small neuroectodermal structures derived from the neural crest and having migrated parallel to the autonomic nervous system $[10,21,22]$. The truncal neural crest gives rise to metameric paraganglia, the neural crest to cervicofacial paraganglia [9]. Intercarotid Paraganglia These are the largest in physiological size ( 3 to $5 \mathrm{~mm}$ ). Together with the carotid sinus, they constitute a functional complex that regulates hemodynamic constants. They are located symmetrically on the posterior surface of the carotid bifurcation, at the origin of the external carotid artery. Their vascularization depends on the intercarotid arteries, which originate either from the common carotid artery or, more often, from the external carotid artery. Innervation depends essentially on the glossopharyngeal nerve via the Hering nerve. Macroscopically histologically The carotid corpuscle is an ovoid, sometimes lobulated mass, ranging in color from pale pink to red-brown. Its consistency is firm or soft depending on the degree of vascularization, its surface is smooth or bumpy and well encapsulated, it is so vascularized that it appears angiomatous and bleeds on contact, and its size is variable $[1,2,9]$.

In microscopy The microscopic architecture is made up of small cord-shaped units consisting of 10 to 20 polygonal cells, separated by a reticulinic network and surrounded by a highly vascularized stroma $[9,23]$. In immunohistochemistry, the main cells express general neuroendocrine markers, such as NSE (enolase specific neuron). Chromogranin and metenkephalin [24].

The association of these three markers allows to mark the main cells in $100 \%$ of the cases. These tumors are most often of slow and benign evolution. The possible malignant character of a paraganglioma can only be asserted on the clinical evolution in front of the appearance of local or distant metastases, confirmed histologically.

For the majority of authors, the curative treatment of carotid paragangliomas can only be surgical, any other therapy can only claim to stabilize the tumor [25], Surgery for carotid paragangliomas is one of the most difficult procedures in cervicofacial surgery. It is sometimes disappointing. Embolization This is a pre-therapeutic endovascular occlusion, which represents a therapeutic instrument that is now indispensable, facilitating and allowing previously unthinkable excisions [26,27]. The objectives of this technique are the reduction of vascularization as well as tumor volume and the reduction of intraoperative blood loss [28,29]. However, some tumors are inoperable due to the general condition of the patients, their volume and local extension. Bilateral forms also pose management problems related to surgical complications. The alternative may be radiotherapy, which has been shown to be effective on this type of tumor [30]. Paragangliomas have the reputation of being not very radiosensitive (10, Initially proposed as an exclusive treatment for paragangliomas because of their haemorrhagic nature, a moment dethroned by the development of surgical and then angiographic techniques, radiotherapy is now experiencing a certain revival of interest [31,32]. It is not considered a curative treatment because it does not generally lead to the eradication of the lesion. It leads to regression of the tumor, the residue remaining stable for a long time. 
Systemic therapy in advanced paraganglioma is limited. No prospective trials have been published to guide therapeutic decisions. Variations in the cytotoxic regimen of cyclophosphamide, vincristine and dacarbazine (CVD) and temozolomide have been reported in small retrospective series and case studies, with variable response rates and limited quality data [33,34]. In addition, chemotherapy-related toxicities are common, including myelosuppression, neuropathy, and gastrointestinal toxicity [33]. Sunitib is being evaluated in several Phase II studies and has shown modest improvements in response rate and progression-free survival [35]. Better treatment options are urgently needed.

\section{Conclusion}

Carotid paragangliomas remain rare, poorly known and often benign conditions. They require early diagnosis and adequate multidisciplinary management by surgeons, oncologists and radiotherapists depending on the stage. However, reported metastases have proven the possible malignancy of paragangliomas The clinical picture is not always suggestive of a paraganglioma. Surgery remains the reference curative treatment. Radiotherapy is only used in the case of recurrence, inextirpable tumor or surgical contraindications.

\section{References}

1. Bougrine F, Maamouri F, Doghri R, Msakni I, Sabbegh Znaidi N, et al. (2008) Une tumeur rare du glomus carotidien. Journal des Maladies Vasculaires 33(4-5): 214-217.

2. Drissia M, Lamrania Y, Maaroufia M, Essatarab Y, N Kanjaa, et al. (2010) Masse cervicale chez un adulte. Feuillets de radiologie 50(5): 268-272.

3. Roden D, Myssiorek D (2016) Neck management in malignant head and neck paragangliomas. Operative Techniques in Otolaryngology 27(1): 41-46.

4. Ricardo José González-Orús Álvarez-Morujo, Miguel Ángel Arístegui Ruiz, Julia da Costa Belisario, Tomás Martinez Guirado, Bartolomé Scola Yurrita (2015) Head and Neck Paragangliomas: Experience in 126 Patients With 162 Tumours. Acta Otorrinolaringol Esp 66(6): 332-341.

5. Lalyaa I, Mechchat A, Lalya I, Kebdani T, K.Hassouni, et al. (2011) Efficacité de la radiothérapie en première intention d'un paragangliome carotidien non résécable. Journal des Maladies Vasculaires 36(3): 185188.

6. Céruse P, Ambrun A, Cosmidis A, Dubreuil C, Feugier P (2013) Paragangliomes latérocervicaux. EMC Oto-rhino-larayngologie 8(4): $1-15$.

7. Makeieff M, Thariat J, Reyt E, Righini CA (2012) Traitement des paragangliomes cervicaux. Annales françaises d'oto-rhino-laryngologie et de pathologie cervico-faciale 129(6): 361-367.

8. Geoff A Chiu, Andrew I Edwards, Shakeel Akhtar, Jonathan C Hill, Isabelle M Hanson (2010) Carotid body paraganglioma manifesting as a malignant solitary mass on imaging: a case report. Oral Surg Oral Med Oral Pathol Oral Radiol Endod 109(4): e54-e58.

9. Thomassin JM, Deveze A, Marciano S (2002) Paragangliomes latérocervicaux. EMC Oto-rhino-larayngologie 20(955): 1-14.

10. Tijani Y, Chtata H, Kouvidjin BT, Abissegue Y, Taberkant M (2012) Les paragangliomes cervicaux : Une expérience chirurgicale à propos de 12 cas. Journal des Maladies Vasculaires 37(6): 291-294.
11. Pałasz P, Adamski Ł, Studniarek M (2015) Paragangliomas: À Propos of Two Cases.Diagnostics and Treatment. Pol J Radiol 80: 411-416.

12. Unlu Y, Becit N, Ceviz M, Kocak H (2009) Traitement des tumeurs du corpuscule carotide et des paragangliomes familiaux : revue de 30 ans d'experience. Ann Vasc Surg 23(5): 667-672.

13. Alaoui M, Bouzarwata A, El Idrissi R, Benzirare A, N Sedki, et al. (2007) Paragangliomes multiples : à propos de deux cas. Archives des maladies du cœur et des vaisseaux 100(6-7): 582-586.

14. Rodríguez-Cuevas S, López-Garza J, Labastida-Almendaro S (1998) Carotid body tumors in inhabitants of altitudes higher than 2000 meters above sea level. Head Neck 20(5): 374-378.

15. (1996) Paragangliomes carotidiens à propos de 10 cas et revue de la littérature - 131 -Langman J. Embryologie médicale 23: 123-154.

16. Luca Del Guercio, Donatella Narese, Doriana Ferrara, Lucia Butrico, Andrea Padricelli, et al. (2013) Carotid and Vagal Body Paragangliomas. Translational Medicine 6(3): 11-5.

17. Demattè S, Di Sarra D, Schiavi F, Casadei A, Opocher G (2012) Role of ultrasound and color Doppler imaging in the detection of carotid paragangliomas. J Ultrasound 15(3): 158-163.

18. Barbara Peric, Ziva Pohar Marinsek, Breda Skrbinc, Maja Music, Ivana Zagar, et al. (2014) A patient with a painless neck tumour revealed as a carotid paraganglioma: a case report. World J Surg Oncol 12: 267-271.

19. McCaffrey TV, Myssiorek D, Marrinan M (2001) Head and neck paragangliomas: Physiology and Biochemistry. Otolaryngol Clin North Am. 34(5): 837-844.

20. Papaspyrou K, Mewes T, Rossmann H, Fottner C, Brigitte SchneiderRaetzke, et al. (2012) Head and neck paragangliomas: Report of 175 patients (1989-2010). Head Neck 34(5): 632-637.

21. Amato A, Bianco T, Compagna R, Siano M, Esposito G, et al. (2014) Surgical resection of carotid body paragangliomas: 10 years of experience. The American Journal of Surgery 207(2): 293-298.

22. F B Meyer, T M Sundt Jr, B W Pearson (1986) Carotid body tumors: a subject review and suggested surgical approach. J Neurosurg 64(3): 377-385.

23. Santi R, Franchi A, Saladino V, Massimo Trovati, Giovanna Cenacchi, et al. (2015) Sclerosing paraganglioma of the carotid body: a potential pitfall of malignancy. Head Neck Pathol 9(2): 300-304.

24. Filho PA, Rapoport A, Alves VA, Denardin OV, Sobrinho J, et al. (2001) Paragangliomas of the head and neck: clinical, morphological and immunohistochemical aspects. Sao Paulo Med J 119(3): 114-118.

25. Zidi A, Bouaziz N, Mnif N, Kribi L, Kara M, et al. (2000) Tumeurs du corpuscule carotidien: Apport des différentes techniques d'imagerie. A propos de six observations. J Radiol 81(9): 953-957.

26. Tripp HF, Fail PS, Beyer MG, Gary AChaisson (2003) New approach to preoperative vascular exclusion for carotid body tumor. J Vasc Surg 38(2): 389-391.

27. Jackson R.S, Myhill JA, Padhya TA, McCaffrey JC, McCaffrey TV, et al. (2015) The Effects of Preoperative Embolization on Carotid Body Paraganglioma Surgery: A Systematic Review and Meta-analysis. Otolaryngol Head Neck Surg 153(6): 943-950.

28. Ozyer U, Harman A, Yildirim E, Aytekin C, Akay TH, et al. (2010) Devascularization of Head and Neck Paragangliomas by Direct Percutaneous Embolization. Cardiovasc Intervent Radiol 33(5): 967975.

29. Yilmaz S, Sindel T, Tuncer R, Luleci E (2003) Preoperative Embolization of Carotid Body Tumors with Microsphere Particles. Annals of Vascular Surgery 17(6): 697-698. 
30. Silva ES, Tozzi FL, Paiva FHM, Sukys GA (2000) Bilateral carotid body paraganglioma: case report. Sao Paulo Med J 118(1): 13-16.

31. Dupin C, Lang P, Dessard-Diana B, Simon JM, Cuenca X, et al. (2014) Treatment of Head and Neck Paragangliomas With External Beam Radiation Therapy. Int J Radiat Oncol Biol Phys 89(2): 353-359.
32. Zabel A, Milker-Zabel S, Huber P, Schulz-Ertner D, Schlegel W, et al. (2004) Fractionated stereotactic conformal radiotherapy in the management of large chemodectmas of the skull base. Int J Radiat Oncol Biol Phys 58(5): $1445-1450$. 